\title{
Application of energy routers in railway power supply systems
}

\author{
Yuri Bulatov ${ }^{1, *}$, Andrey Kryukov ${ }^{2,3}$, and Grigory Arsentyev ${ }^{3}$ \\ ${ }^{1}$ Bratsk State University, Bratsk, Russia \\ ${ }^{2}$ Irkutsk State Transport University, Russia \\ ${ }^{3}$ Irkutsk National Research Technical University, Irkutsk, Russia
}

\begin{abstract}
The development of electric power industry requires transition to the technological platform, encouraging implementation of smart grids. To set up these grids it is necessary to apply smart technologies of power supply system control modes, as well as interfaces, ensuring the connection of renewable energy sources. These interfaces may be represented by energy routers. The paper discusses the results of simulating emergency modes, caused by short circuits in $10 \mathrm{kV}$ and $0.4 \mathrm{kV}$ grids of non-traction users, connected via energy routers to the railway power supply system. The studies were performed in MATLAB system. Simulation results showed that the application of controlled energy routers for the non-traction user power supply completely removes electric power quality problems, allows for reliable integration of distributed generation plants into the power supply system, and limits short circuit currents and reduces the depth of the AC failure.
\end{abstract}

\section{Introduction}

The development of electric power industry requires transition to the technological platform, encouraging implementation of smart grids. To set up these grids it is necessary to apply smart technologies of power supply system control modes [1-7], as well as interfaces, ensuring the connection of renewable energy sources. These interfaces may be represented by energy routers (ER) [8-10]. Completed studies [14] confirm that the use of ERs enables to improve the electric power quality in $0.4 \mathrm{kV}$ grids, connected to the regional winding of traction transformers.

The work considers an ER three-step topology and also presents the results of simulating emergency modes, caused by short circuits in $10 \mathrm{kV}$ and $0.4 \mathrm{kV}$ grids of non-traction users, connected to the railway power supply system with an ER.

\footnotetext{
*Corresponding author: bulatovyura@yandex.ru
} 


\section{Energy router structure}

An ER is basically a solid-state transformer (SST). So far numerous SST configurations have been suggested $[15,16]$. They may be categorized into the following major groups: a singlestep topology with AC forward conversion; a two-step topology with a low-voltage DC link; a two-step topology with a high-voltage DC link; a three-step topology with low and high voltage DC links.

A single-step topology is the earliest ER topology. This topology includes a forward or matrix AC-AC converter and does not have a DC link. Owing to the widespread implementation of DC devices, including photovoltaic panels, high power storage batteries, fuel cells, the topologies with DC links are in the focus of attention.

An ER three-step topology, shown in fig. 1, is considered the best solution for smart grids. It has DC links and, therefore, may provide auxiliary services to both high-voltage and lowvoltage direct current consumers.

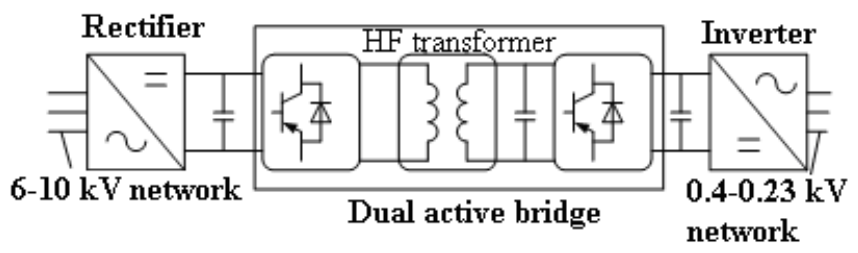

Fig. 1. An ER three-step topology with high and low voltage direct current links.

In low and medium power ER layouts a high voltage inverter may use metal oxide field effect transistors (MOSFET), which show high dynamic performance, enabling to work with the frequency of up to $100 \mathrm{kHz}$. The operating frequency of these ERs is approximately 20 $\mathrm{kHz}$. However, these semiconductor elements have limitations on current transfer capacity, 100 A maximum. In the high voltage converter of the ER model under consideration bipolar IGBT transistors are applied. They can commutate currents over $1 \mathrm{kA}$. The efficient use of this transistor is limited by the switch frequency, under which losses are permissible ensuring the conversion efficiency factor over $90 \%$. This frequency must not exceed $5 \mathrm{kHz}$.

\section{Model description and study results}

In the MATLAB system we developed a simulation energy router model [8], whose layout is given in Fig. 1. The model enables to connect $\mathrm{AC}$ and $\mathrm{DC}$ distributed generation plants.

For the purpose of the research a separate 4.66 MVA non-traction use power supply region was simulated, including distributed generation plants, powered by renewable energy resources: solar power station and a micro hydro power station. Therewith, the power supply region was equipped with two simultaneously operating ERs with 3 MVA high voltage solid state transformers (fig. 2).

The solar power station model was made using a MATLAB PV Array unit built on 100 parallel and 10 serial photovoltaic modules. The simulation involved two solar power stations with the total power of $215 \mathrm{~kW}$, connected to the direct current buses on the $0.4 \mathrm{kV}$ side. For the micro hydro power station with the power of $250 \mathrm{kVA}$ and voltage $0.4 \mathrm{kV}$ we used a standard model of a synchronous generator (SG) from the SimPowerSystems package. The description of the applied models of the solar power station, micro hydro power station and synchronous generator regulators (automatic excitation control and automatic speed regulator) is provided in $[4,14]$. 


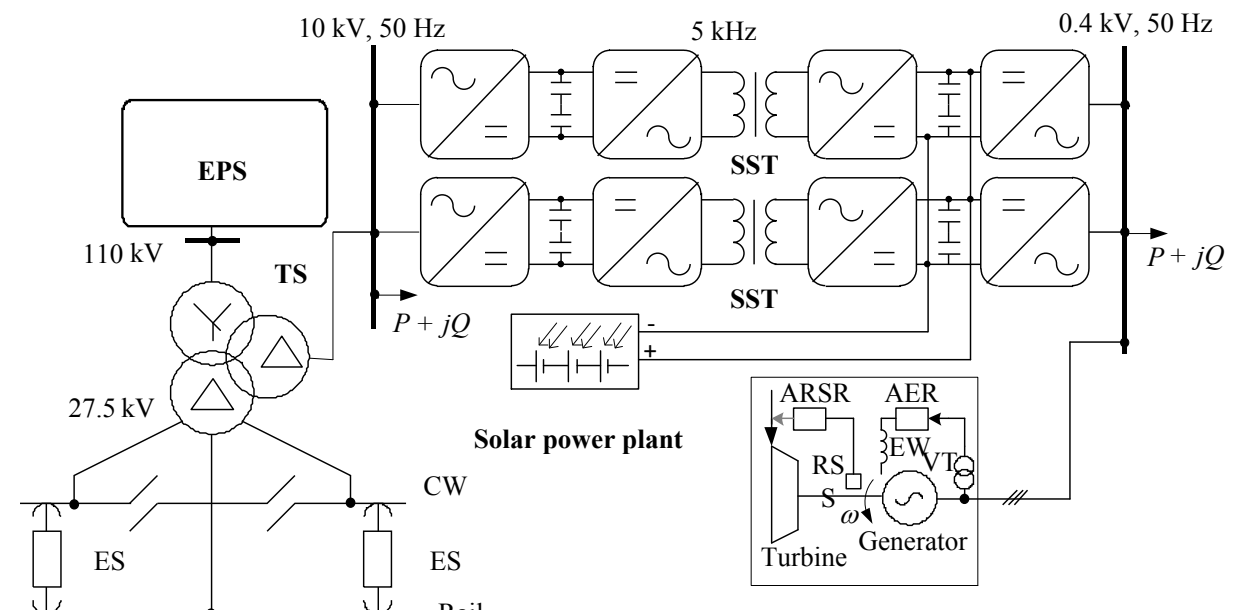

Generator micro hydropower plant

Fig. 2. A fragment of a railway power supply system: EPS - electric power system; TS- traction substation; ES- electric stock; SST - solid-state transformer; CW - contact wire; RSS -rotor speed sensor; EW - excitation winding; VT - voltage transformer; AER - automatic excitation regulator; ARSR - automatic rotor speed regulator.

The results of simulation show that the application of ERs in railway power supply systems enables to solve non-traction users' problem of electric power quality. Oscillography voltage records on $0.4 \mathrm{kV}$ buses when using traditional transformers $10 / 0.4 \mathrm{kV}$ and energy routers are given in Fig. 3. The figure also presents the factors of voltage harmonics and the asymmetry factors on reverse sequence.
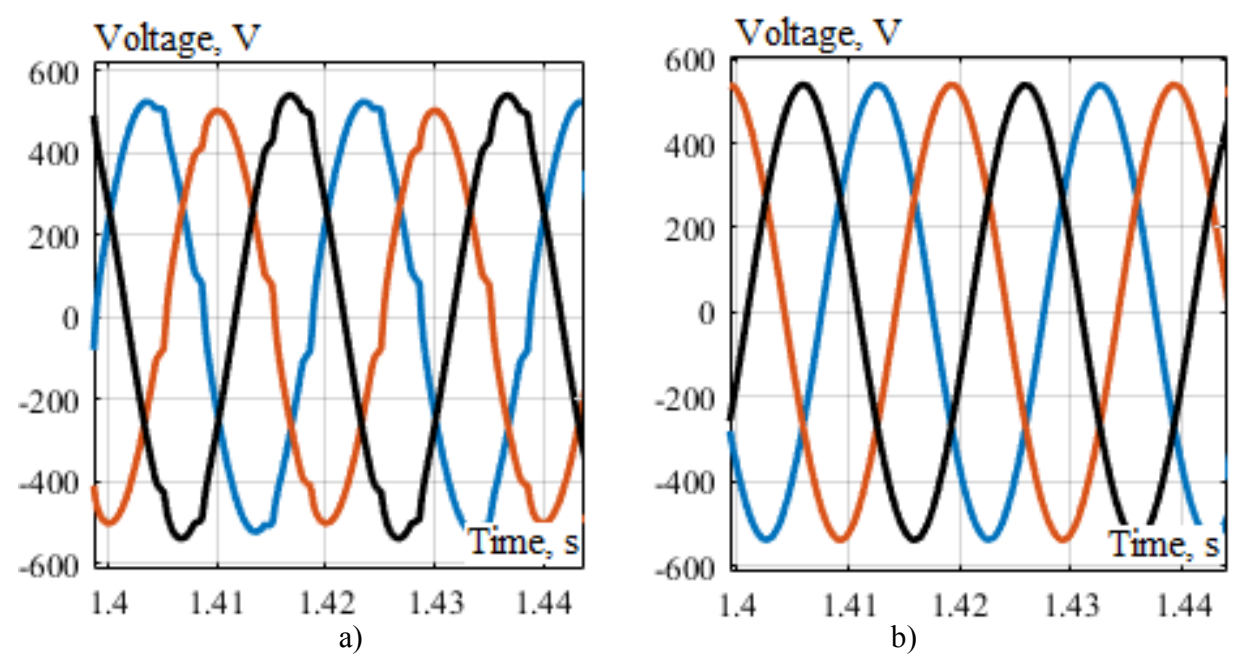

Fig. 3. Oscillograms of voltages on $0.4 \mathrm{kV}$ buses of non-railway consumers: a) transformer: $k_{U a b}=4.6$ $\%, k_{U b c}=4.7 \%, k_{U c a}=3.4 \%, k_{2 U}=4.6 \%$; b) energy router: $k_{U a b}=k_{U b c}=k_{U c a}=0.3 \%, k_{2 U}=0.05$ $\%$.

The results of simulating emergency modes, caused by three-phase short circuits (SCs) in ER connection units on $10 \mathrm{kV}$ buses and in $0.4 \mathrm{kV}$ grid, provide evidence that distributed 
generation plants considerably increase short circuit currents in the connection point, but have low effect on SC currents in the $10 \mathrm{kV}$ grid.

To study the ER effect on the currents in the emergency modes, caused by different types of short circuits on $0.4 \mathrm{kV}$ buses, simulation was performed with no connected distributed generation plants. The simulation results are consolidated in table 1 and also given as oscillography records of instantaneous currents and voltages for the three-phase SC in Fig. 4 and 5 .

Table 1. Short circuit currents on $0.4 \mathrm{kV}$ buses.

\begin{tabular}{|c|c|c|c|c|c|}
\hline $\begin{array}{l}\text { Power Supply } \\
\text { System } \\
\text { operation mode }\end{array}$ & \multicolumn{2}{|l|}{ SC currents nype } & $\begin{array}{c}\text { One- } \\
\text { phase } \\
\text { SC }\end{array}$ & $\begin{array}{l}\text { Two- } \\
\text { phase } \\
\text { SC to } \\
\text { earth }\end{array}$ & $\begin{array}{c}\text { Three- } \\
\text { phase } \\
\text { SC }\end{array}$ \\
\hline \multirow{6}{*}{$\begin{array}{l}\text { 1. Application of } \\
\text { the traditional } 10 / \\
0.4 \mathrm{kV} \text { transformer }\end{array}$} & \multirow[t]{3}{*}{ Surge current, kA } & $i_{\mathrm{A}}$ & 17,94 & 23,52 & 22,51 \\
\hline & & $i_{\mathrm{B}}$ & 11,34 & 18,02 & 19,99 \\
\hline & & $i_{\mathrm{C}}$ & 9,61 & 9,86 & 15,22 \\
\hline & \multirow{3}{*}{$\begin{array}{l}\text { Periodical current at the initial } \\
\text { time (actual value), kA }\end{array}$} & $I_{\mathrm{A}}$ & 12,04 & 13,55 & 13,29 \\
\hline & & $I_{\mathrm{B}}$ & 7,69 & 10,6 & 11,4 \\
\hline & & $I_{\mathrm{C}}$ & 6,83 & 6,9 & 10,47 \\
\hline \multirow{6}{*}{$\begin{array}{l}\text { 2. Energy router } \\
\text { application }\end{array}$} & \multirow[t]{3}{*}{ Surge current, kA } & $i_{\mathrm{A}}$ & 14,71 & 19,88 & 20,25 \\
\hline & & $i_{\mathrm{B}}$ & 11,14 & 16,13 & 19,23 \\
\hline & & $i_{\mathrm{C}}$ & 7,85 & 9,97 & 16,55 \\
\hline & \multirow{3}{*}{$\begin{array}{l}\text { Periodical current at the initial } \\
\text { time (actual value), } \mathrm{kA}\end{array}$} & $I_{\mathrm{A}}$ & 11,25 & 12,12 & 9,77 \\
\hline & & $I_{\mathrm{B}}$ & 7,9 & 7,08 & 9,76 \\
\hline & & $I_{\mathrm{C}}$ & 5,43 & 7,05 & 9,75 \\
\hline
\end{tabular}

\section{Current, kA}

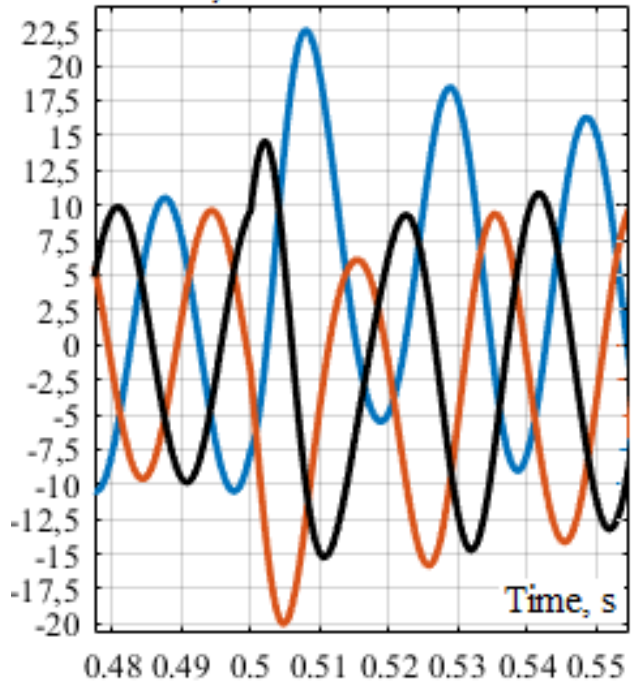

a)

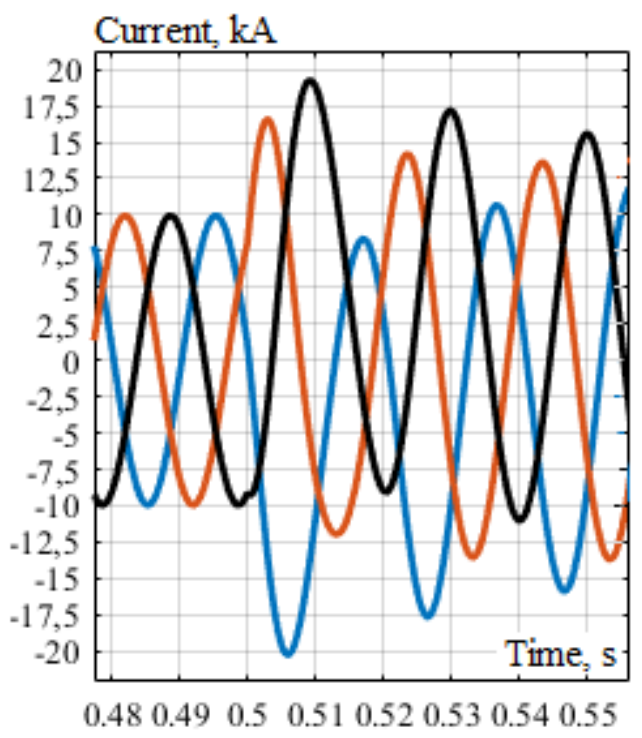

b)

Fig. 4. Oscillograms of instantaneous currents values on $0.4 \mathrm{kV}$ buses with three-phase SC: a) transformer; b) energy router. 


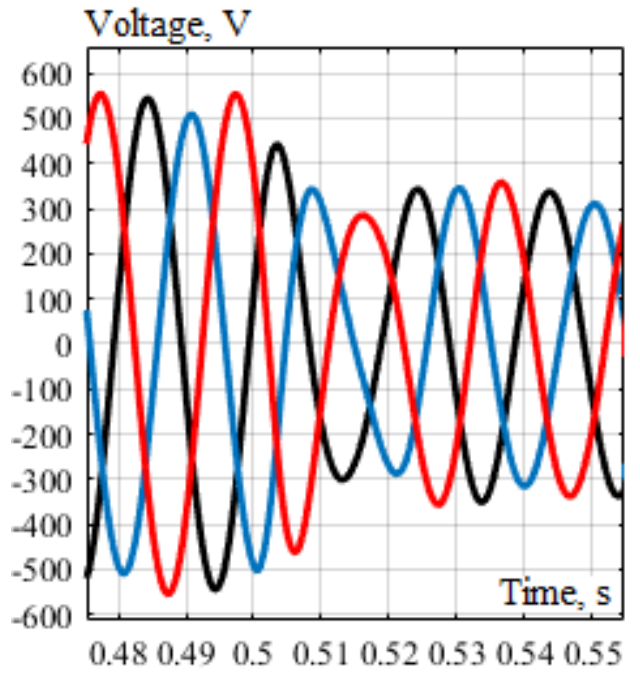

a)

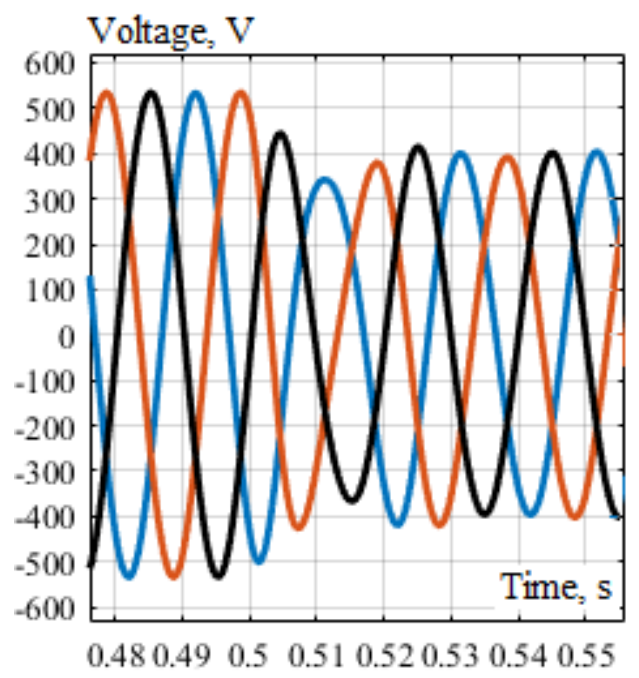

b)

Fig. 5. Oscillograms of instantaneous voltages values on $0.4 \mathrm{kV}$ buses with three-phase SC: a) transformer; b) energy router.

The analysis of the simulation findings shows that an energy router enables to limit short circuit currents compared to a traditional transformer; at the same time surge currents are limited to higher degree. In the above example the maximum surge current reduction when using an ER was observed under a two-phase SC to earth (earth fault) and was $15 \%$. The energy router also enables to reduce the failure depth under a remote short circuit: in this example by $14 \%$ on average.

\section{Conclusion}

Following the simulation results the conclusion below may be made:

1. The use of the energy router to connect non-traction railway users enables to remove problems with the electric power quality and ensures reliable integration of distributed generation plants into the power supply system. Thus, energy routers may be efficiently used in the trunk railway AC power supply systems as the elements ensuring the control of the power flows and the connection of distributed generation plants.

2. An SST-based energy router allows for limiting short circuit currents compared to a traditional transformer.

3. The use of an energy router compared to a traditional transformer enables to reduce the voltage failure depth under a remote short circuit.

\section{References}

1. J. Wang, A.Q. Huang, W. Sung, Y. Liu, B.J. Baliga, IEEE Industrial Electronics Magazine 3-2, 16-23 (2009)

2. B.M. Buchholz, Z.A. Styczynski, Smart Grids - Fundamentals and Technologies in Electricity Networks (Springer,Verlag Berlin Heidelberg, 2014)

3. Yu.N. Bulatov, A.V. Kryukov, K.V. Suslov, Far East Journal of Electronics and Communications 17-5, 1197-1212 (2017) 
4. A.V. Kryukov, S.K. Kargapol'cev, Yu.N. Bulatov, O.N. Skrypnik, B.F. Kuznetsov, Far East Journal of Electronics and Communications 17-5, 1127-1140 (2017)

5. F.N. Mohsen, M.S. Amin, H. Hashim, IEEE 7th International Power Engineering and Optimization Conference (PEOCO) (2013) DOI:10.1109/PEOCO.2013.6564586

6. K. Suslov, N. Solonina, V. Stepanov, International symposium on smart electric distribution systems and technologies EDST 2015 Proceedings, 260-264 (2015)

7. Yu.N. Bulatov, A.V. Kryukov, 2nd International Conference on Industrial Engineering, IEEE Conference Publications, 1-6 (2016) DOI: 10.1109/ICIEAM.2016.7911456

8. A. Juneja, S. Bhattacharya, 2011 IEEE International Conference on Smart Grid Communications (SmartGridComm), 31-36 (2011)

9. A.Q. Huang, M.L. Crow, G.T. Heydt, J.P. Zheng, S.J.N.I.S. Dale, Proceedings of the IEEE (2010) DOI: 10.1109/JPROC.2010.2081330

10. R.P. Alzola, G.V.Gohil, L. Mathe, M. Liserre, F. Blaabjerg, Proceedings of the IEEE Energy Conversion Congress and Exposition: ECCE 2013 (2013) DOI: 10.1109/ECCE.2013.6646726

11. A. Ghasemi, M. Hojiat, M. H. Javidi, Proc. 2nd Iranian Conf. Smart Grids, 1-7 (2012)

12. C. Lin, H. Zhao, X. Liu, Trans. China Electro Technical Soc. 30-11, 37-44 (2015)

13. M. Schulze, L. Friedrich, M. Gautschi, Proc. Int. Conf. Sustainable Energy Technologies, 83-88 (2008)

14. Yu. N. Bulatov, A.V. Kryukov, G.O. Arsentyev, Electrical equipment: operation and repair 4, 64-69 (2018)

15. X. Mao, S. Falcones, R. Ayyanar, Proc. FREEDM Annual Conference 2009, North Carolina State University, 217-220 (2009)

16. S.G. Bansode, P.M. Joshi, Proceedings of 11th IRF International Conference, Pune, India, 15-21 (2014) 